\title{
Fosfomycin in vitro resistance of Escherichia coli from the community
}

\author{
Authors \\ Caroline M Biondo ${ }^{1}$ \\ Jaime L Rocha ${ }^{2}$ \\ Felipe Francisco Tuon ${ }^{3}$ \\ ${ }^{1}$ Division of Infectious and \\ Parasitic Diseases, Hospital \\ Universitario Evangelico \\ de Curitiba, Curitiba, PR, \\ Brazil - MS \\ ${ }^{2}$ Division of Microbiology, \\ Frischmann Aisengart/ \\ DASA Medicina \\ Diagnóstica, Curitiba, PR, \\ Brazil - MD \\ ${ }^{3}$ Hospital Universitário \\ Evangélico de Curitiba
}

Submitted on: 08/01/2010 Approved on: 08/02/2010

Correspondence to: Infectious and Parasitic Diseases Clinic

Hospital Universitário Evangélico de Curitiba Alameda Augusto Stellfeld 1908, 30. andar 80730-150 SCIH Bigorrilho, Curitiba, Brazil

flptuon@gmail.com

We declare no conflict of interest.
It is common practice in many places all over Brazil to use fosfomycin in the treatment of uncomplicated urinary tract infections, although resistance profile is not currently well-known in our country.

We would like to report the findings of in vitro activity of fosfomycin against 240 nonduplicate consecutive E. coli strains isolated from community urinary samples $\left(>10^{5} \mathrm{CFU} /\right.$ $\mathrm{mL}$ in October 2009) from Curitiba (Paraná, Brazil). Susceptibility test were performed according to CLSI, using disk diffusion with $200 \mathrm{mg}$ of fosfomycin disk with zone diameter breakpoint as recommended by CLSI. ${ }^{1}$ Clinical data were not evaluated and no statistical analysis was performed, considering the descriptive nature of the study.

The susceptibility of $E$. coli to fosfomycin was $98.8 \%$ and to other antibiotics ranged from 66.3 - $99.2 \%$ as follows: sulfamethoxazole $(66.3 \%)$, nalidixic acid $(78.3 \%)$, quinolones $(81.3 \%$, including ciprofloxacin, levofloxacin and norfloxacin), amoxicillin/clavulanic acid (88.7\%), nitrofurantoin (99.2\%) and ceftriaxone (99.2\%).

In the present study E. coli isolates from patients with urinary infection were highly susceptible to fosfomycin. These data suggest that fosfomycin may be a good alternative for first line antimicrobial treatment of uncomplicated low urinary tract infections. ${ }^{2}$ It is well-known that variations in bacterial resistance patterns for Escherichia coli occur amongst different populations. ${ }^{3}$ It is mandatory for clinicians to be constantly aware of the local bacterial resistance profiles in order to update empirical antimicrobial regimens. Fosfomycin also seems to be a reasonable option for bacteria other than E. coli, such as Enterococcus. ${ }^{4}$ In our area, fosfomycin is a good option, but this cannot be extrapolated to other regions of the country. On going surveillance studies are needed in the country.

[Braz J Infect Dis 2011;15(1):96]@Elsevier Editora Ltda.

\section{REFERENCES}

1. CLSI. Performance Standards for Antimicrobial Susceptibility Testing; Twentieth Informational Supplement. CLSI document M100-S20. Wayne, PA. Clinical and Laboratory Standards Institute 2010.

2. Popovic, M, Steinort, D, Pillai, S, Joukhadar, C. Fosfomycin: an old, new friend? Eur J Clin Microbiol Infect Dis 2010; 29:127-42.

3. Calbo, E, Romani, V, Xercavins, $M$ et al. Risk factors for community-onset urinary tract infections due to Escherichia coli harbouring extended-spectrum beta-lactamases. J Antimicrob Chemother 2006; 57:780-3.

4. Superti, S, Dias, CA, d'Azevedo, PA. In vitro fosfomycin activity in vancomycin-resistant Enterococcus faecalis. Braz J Infect Dis 2009; 13:123-4. 